\title{
STRATEGIC DEVELOPMENT OF PERSONAL AND INTERPERSONAL SKILLS
}

\author{
Peter TÖRLIND ${ }^{1}$ and Lars EKLÖF ${ }^{2}$ \\ ${ }^{1}$ Product Innovation, Luleå University of Technology, Sweden \\ ${ }^{2}$ Industrial Design, Luleå University of Technology, Sweden
}

\begin{abstract}
Personal and interpersonal skills are an essential part of design engineers' knowledge and skills, which students rarely feel they work with in a structured way during their education. To improve soft skills, the ideas on developing students' personal and interpersonal skills were implemented in designimplement experience, a 15 ECTS third-year capstone project for bachelor students. Parallel to the design project, students had to identify personal or interpersonal skills that they wanted to develop during the course. Personal development was done in several stages: Identification of personal development areas (PDA), discussion of PDA in group meetings, creating a development plan, personal coach meetings, status update and a final reflection

The results of this paper are based on teachers notes, written documentation and course evaluations. In the analysis, development areas were categorised using the CDIO Syllabus 2.0, where 59\% was classified as Personal skills and $40 \%$ related to Interpersonal skills. The perseverance subset was the most common one identified. Other areas included lack of self-confidence, conflict mediation, creating a constructive dialogue between team members and time and resource management. Using this approach for three years and analysing the implementation, we can conclude that it has improved students' personal and interpersonal skills. The results also highlight that students like to be challenged to change their professional conduct.
\end{abstract}

Keywords: CDIO, soft skills, integrated learning, personal development

\section{INTRODUCTION}

Industrial design engineering (IDE) is a Bachelor/Master programme at the Luleå University of Technology. The IDE-programme integrates industrial design with engineering design, using human needs and requirements as main incentives for developing students' products, processes, and systems building skills. By tradition, various subjects such as usability, aesthetics, design methods, ergonomics, human work environment and design theory have been interspersed with more traditional engineering subjects such as math's, physics, solid mechanics, material science. Since 2015 we have been a part of the CDIO-initiative and adapted the programmes to that framework [1]. One of the fundamental ideas of CDIO is integrated learning experiences, i.e., activities that lead to the acquisition of disciplinary knowledge, combined with activities that focus on enhancing personal and interpersonal skills and product, process, and system building skills [2]. Integrated learning experiences are often implemented in real design challenges, something that CDIO calls design-implement experiences.

When developing a programme, it is crucial to have a holistic view and break down the programme's overall goals and create courses that build on each other, complement each other, and a system that supports students to develop their knowledge and skills in a self-regulated way. To support this, a competence profile [3] has been created for the IDE programme to function as a framework supporting both students and teachers understanding of what competencies they need to build to work as an Industrial Design Engineer.

In many of our design-implement experiences, personal and interpersonal skills are visualised and assessed through a workbook approach [4] in which students describe their progress in the projects through cycles of reflection. A typical workbook consists of written text, i.e., literature reviews and methods employed, and sketches and photos illustrating the process and its results. The most important part of the workbook is reflections and learning that deals with learning outcomes in terms of lessons learned, experiences and challenges to address in upcoming projects. 
When analysing the programme's courses, it was clear that courses focus on developing disciplinary knowledge and lack systematic development of personal and interpersonal skills. We found that few courses explicitly included personal qualities and professional conduct; feedback was often done on their project skill of being part of a team but not really on the personal level. In evaluations of the programme, students have expressed a lack of developing interpersonal skills, which is unfortunately common in many programmes in Sweden. In a survey of 11,119 students at Swedish universities in 2007 , students' experiences of support for professional development are disappointing and that $90 \%$ of students perceive that they rarely discuss their individual development with teachers [5]. So, we took this as an opportunity to integrate this into one of our capstone courses.

This paper aims to describe the implementation of a structure to support the individualised development of personal and interpersonal skills.

\section{METHOD}

The ideas on developing students' personal and interpersonal skills were implemented in designimplement experiences, a 15 ECTS (20 week) third-year capstone project for bachelor students. The first implementation of the development of interpersonal and personal skills was implemented in the autumn of 2018 (9 students) and has since then been performed in 2019 (16 students) and 2020 (6 students).

One of the learning objectives is to improve interpersonal skills for project work. In the course, the students work with a design challenge from an external company or organisation. The challenges are quite diverse. For example, in 2019, projects ranged from an innovative user interface for truss calculation, how to improve the city centre, designing the user interface for satellite control, and designing an enclosure for wideband positioning systems.

This paper's analysis is based on teachers notes from discussions with students, written documentation of their development areas, documentation of meetings, and course evaluations. In the course evaluation, specific questions were designed to focus on the structured work on personal development. For the student's development areas, all individual development areas $(n=75)$ were gathered in Excel and then categorised according to the CDIO Syllabus 2.0 (CS2.0) [6], this categorisation was first done by one author and then reviewed by the other author to reach an agreement of the best categorisation. All student quotes have been translated from Swedish and anonymised by the authors.

\section{IMPLEMENTATION}

During the project, the student groups were divided into small teams that worked with their Personal Development Areas (PDA) for 20 weeks. Parallel with the design project, students had to identify personal or interpersonal skills that they wanted to develop during the course. Personal development is done in several phases. See Figure 1 and the section below for details.

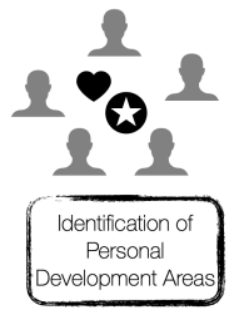

w 1

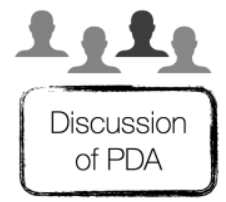

w 2

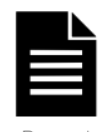

Personal plan

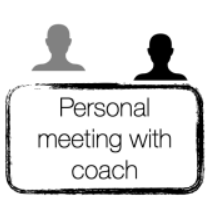

w 10

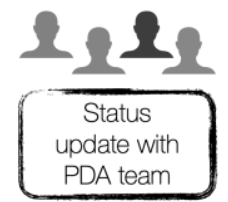

w 15

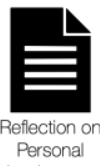

Personal
development plan

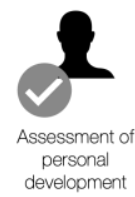

development

Figure 1 Graphical representation of this process

- Identification of PDA (week 1). To help identify personal challenges, each person in their teams had to write something positive, "I like..." and a development area, "I wish..." about the other team members. Then, the students had to select areas they wanted to improve during the course. To help them identify the issues, they should prepare at least two areas and describe What is the issue?, Where is it happening?, When is it happening?, Why is it happening?, How can you overcome this problem? Who do you need to get involved?

- Discussion of PDA (week 2). This was arranged in small meetings with members from other teams. In the discussion, each student got about 20 min each where they presented their development area. 
Other students commented to clarify the issue and came with feedback on how they could work with the development area.

- $\quad$ Creating a development plan (week. 2), Each student then described their selected development areas, the feedback they got in the discussion meeting and explained how to work with the issue during the course (including prioritisation, goals, means to achieve the goals). The personal development plan was sent to the teachers.

- $\quad$ Personal meeting with the coach (week 10) during this meeting, the development plan's status was discussed with one of the teachers.

- $\quad$ Status update with the PDA team (week 15), update current status, how the student has worked with the different areas, and receive feedback from both students and teachers.

- Final reflection on personal development (week 20), reflection on the development process, what has been achieved and how to proceed in the future.

- Assessment of the development plan includes the identification and analysis of the PDA, how active the student has been in the discussions, and how they reflect on the progress of their challenges in the course.

\section{RESULTS}

The overall feedback from students was very positive. From the course evaluation Overall impression of the course (student rates the course between 1-5): 4,6 (2018); 4,8 (2019); 4,8 (2020). One student summarises the course as "I like the challenge of developing something new with my team, and at the same time, have the opportunity to identify and work with some of my weak areas. I needed the input and support from you and other students to dare to deal with my fear of asserting my opinion.".

\subsection{Personal Development Areas}

When categorising the student's PDA according to the CDIO Syllabus, 59\% was classified as Personal and professional skills and attributes and $40 \%$ related to Interpersonal skills.

Table 1. The categorisation of development areas using the CDIO Syllabus 2.0

\begin{tabular}{|l|c|}
\hline CDIO Syllabus 2.0 categorisation & $\mathrm{n}$ \\
\hline 2.3.3 Prioritisation and Focus & 5 \\
\hline 2.4.1 Initiative and Willingness to Make Decisions in the Face of Uncertainty & 1 \\
\hline 2.4.5 Self-Awareness, Metacognition and Knowledge Integration & 2 \\
\hline 2.4.7 Time and resource management & 6 \\
\hline 3.1.1 Forming Effective Teams & 2 \\
\hline 3.2.7 Inquiry, Listening and Dialog & 6 \\
\hline 3.2.8 Negotiation, Compromise and Conflict Resolution & 2 \\
\hline 4.3.4 Development Project Management - Configuration management and documentation & 1 \\
\hline 2.4.2 Perseverance, Urgency and Will to Deliver, Resourcefulness and Flexibility & 23 \\
\hline 3.1.4 Team Leadership & 2 \\
\hline 3.1.2 Team Operation & 12 \\
\hline 3.2.2 Communications Structure & 3 \\
\hline 2.3.1 Thinking Holistically & 2 \\
\hline 2.5.2 Professional Behaviour & 1 \\
\hline 2.5.7 Time and Resource Management & 4 \\
\hline 3.1.3 Team Growth and Evolution & 1 \\
\hline Other & 2 \\
\hline Sum & 75 \\
\hline
\end{tabular}

\subsubsection{Perseverance, Urgency and Will to Deliver, Resourcefulness and Flexibility}

This is part of the second building block of the syllabus, which describes the personal and professional skills and attributes. In the analysis, the Perseverance, Urgency and Will to Deliver, Resourcefulness and Flexibility subset was the most common ones identified. A common reflection among the students was that they find it challenging to stay focused on their task for an extended period: "I have also watched scientific TV shows about the brain and what disadvantages social media and digital products have. The knowledge I have gained from these sections is that it is good not to have the phone on the table in front of yourself, because you lose attention to what you are doing when it rings/vibrates or lights up. It thus receives more attention than the project receives.". Another common type of comment in this area was the lack of self-confidence expressed in their self-assessments, which harms their work. "All of these are things I have known about before but which I have not really taken to heart. I have always been a person who enjoys giving. If I do not give anything of value, then why should I give?". 
"I have long had a bad self-confidence regarding myself and what I stand for. Maybe that's why I've been afraid of conflict and afraid to call strangers. But when I have taken the time to work on the above points, my self-confidence has also increased.".

The third area of interest in this category was the lack of perseverance, described in different ways: "The bottom line is that it does not have much to do with the lack of commitment, but to do something that evokes my interest and is in line with what I find interesting.". "I have a hard time getting things done if I do not have pressure on me. So, in the future, I will try to put that pressure on myself to do things on time. It is often the case that I am not satisfied with things that I had done before the time ran out, and by putting pressure on myself, I can have more time to be satisfied.".

\subsubsection{Team Operation}

The CS2.0 [6] 3.1.2 Team operation contains more operative elements of teamwork and includes goals and agenda, planning and facilitation of meetings, effective communication, feedback, and empowering team members. In our analysis, this was the second most common area, and within this area, conflict mediation was the most common one. Previously many students tried to avoid conflicts and now challenged themselves to change this behaviour "I will not wait to act but to take the lead role and act immediately the first time it happens so that you immediately show that it is not accepted and that you do not end up in a vicious spiral by letting it go 'this time,". A remedy for this was described by another student "I have forced myself to start jumping into discussions in a better way, instead of just slipping along, I have chosen to share my opinions if I do not agree with anything. The more I have done it, the easier it has actually become.". Another student described the balance of creating a shared goal between the team members "Regardless of what makes the goals among the group members different, the differences will need to be managed for a successful collaboration. To cope with this, compromises and agreements between the group members are required.". Several students got feedback that they were 'slacking' when they often were terrible at communicating what they had done; "I also realised that I needed to pull me together and start communicating for NN when I did 'extra' things.".

Empowering the team and giving positive and valuable feedback was also acknowledged. One of the project leaders encouraged others with positive feedback, which created a positive atmosphere in the group that created an excellent group dynamic. Another project leader reflected on team members' motivation that "I just touched the surface but missed to understand the root cause. [...] I was limited to motivate the person while the problem may have been solved through, for example, a change in work style."

\subsubsection{Inquiry, Listening and Dialog}

In the CS2.0 [6] 3.2.7 Inquiry, Listening and Dialog focus on creating a constructive dialogue between team members, listening, and understanding others, asking questions, processing diverse points of view, and recognising other ideas. Several students described that they sometimes had a problem to explain their point of view, their solutions, or that they started an argument because they misunderstood something. One student described the solution by empowering the team to ask questions if they did not understand "Instead, I need to involve my group members by asking questions or getting them to formulate themselves in some other way.". Two other students also described that they often become passive if they were not confident about the area that they were discussing. Their remedy was to ask clarifying questions to really understand the problem, which was a positive experience for the whole team.

\subsubsection{Time and resource management}

In the analysis, another common reflection was the difficulty to be on time for meetings. In Swedish, there is the concept called Tidsoptimist, literally time optimist, a person who (regularly) underestimates how long something takes and therefore gets busy or delayed. In the CDIO Syllabus, there is no clear set of skills that fits this PDA, but we have categorised it as Personal and Professional Skills and Attributes category. Some quotes from the self-assessment were: "I probably do not prioritise meetings and the like high enough in the morning. I also have such an irregular schedule which makes it difficult to get up early the few days I actually have to do it." "I come in late" "I am often late." 


\subsection{Feedback from students}

Feedback from the students (formal and informal course evaluations and reflections) indicated that they appreciated the discussion meetings, often similar problems are identified, and they can together work to strengthen their weak areas. Students also appreciate that they spend time and effort on personal development and not just formal knowledge and skills "also contributed to me having the opportunity to work with my shortcomings but also strengths in 'sharp' mode" as one of the students described the process "Good with much more focus on reflection and improvement. It has given room for self-insight, rather than someone else telling you how you are as a person".

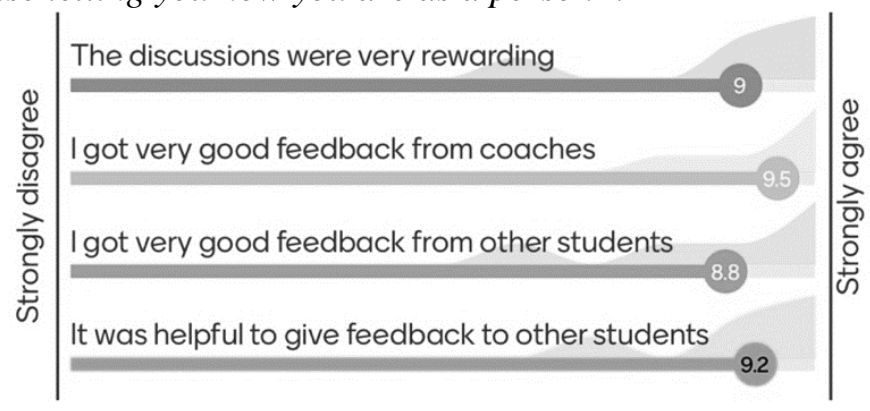

Figure 2 Evaluation of the personal development areas, 2020

Also, it was appreciated was the focus on personal challenges within the project, "I like that there is an aspect that is more about me as a person and not just my role in the work-

Compared to a written workbook, students experienced that this approach was more valuable for their personal development. "It has been very rewarding. In a regular workbook, a lot of time is spent getting the content together. and it is more rewarding to focus on one's own reflections" another student described the personal development work as the "Most educational assignment throughout the education.".

Several students also felt that the openness and the discussions opened up for much more personal discussions within the teams. Everyone was aware that they all worked with various personal challenges during the course. One student described it as "I feel that some of what I shared with me changed both myself and my team."

\section{DIscussion}

Lack of self-confidence was a common PDA that surfaced during the discussion sessions. One of the students was not aware of the fact that she avoided contacting unknown people. Once she was aware of this, she challenged herself to actively work with this PDA and an insightful improvement was expressed in her final self-assessment. Discussing PDAs in groups is an opportunity to address development areas and identify areas that the student may not have been aware of without others' help.

Team conflicts are quite common in design-implement experiences and was also a common topic for our students. In this course, the openness and the students' willingness to change the team behaviour and their own behaviour were higher than in a regular course. It was also clear that actions and behaviours that are usually perceived as irritating and in the end lead to conflicts (coming late, personal focus, misunderstandings) was identified and discussed during group exercises, and thereby highlighting actions that could lead to a conflict and been able to act before it becomes a conflict.

Another area that improved the teamwork was the focus on creating a constructive dialogue between team members, to focus on actually understanding different opinions and making all voices heard. All students were aware of it, but they realised that they could do it much better, especially when several students had that common development area.

After the group discussions where 'Tidsoptimism' arose, it became clear that those who were not time optimists pointed out that it was disrespectful not to show up on time. After this insight, a general improvement in the project groups was quickly noticed.

Some of the students highlighted that it was difficult (at the PDA discussion meetings) to give all people the same amount of focus. In some cases, it was one-way communication, and it was much more rewarding for the students that opened up. The structure of the discussion meeting is something that can be improved in future sessions.

Several students highlighted that they liked the group discussions, presenting their development areas, and discussed how they should work with them. They described that they could solve their problems by 
taking part in others' experience. It also felt good to confirm that others may have the same 'problems' as myself "In my case, it has felt positive that others in the class have had similar reflections on their personality, way of thinking or acting." or that "One forgets that others may also have difficulties that they work with, very important to pay attention to". The students also described that the discussions highlighted the importance to support and empower other students in their teamwork. Working with discussion groups with one member from each project teams also felt like the right approach. The students were more comfortable to discuss problems that arose in their teams. We also decided to put all project leaders in one discussion group, and the focus for those individuals was more on leadership, supporting the team and the individual team members. We also introduced bi-weekly coach meetings with the project leaders focusing on team-related issues and leadership, which project managers much appreciated. As a teacher and leader of the discussion sessions, it felt that we were sometimes scratching on the surface and then revealed something that was a significant personal challenge that students had hidden from others (and even from themselves) for a long time. One of the students described it in the evaluation "Sometimes it got a little too personal [...], I'm ok with that, but others may not be". This is something that the teachers have to be prepared for and have an action plan to get extra support from student health organisations if needed.

The implementation was done in small classes with more than two years of experience working together and can be a challenge to implement in courses with more students. Most of the work is performed in small teams, so it should be possible to achieve with enough teachers to handle the discussion meetings. Parallel to this implementation in this course, we have also introduced the Habits of Minds concept [7] in a similar course to enable students to reflect on their own behaviours. The 16 attributes are used as a starting point to identify strengths and weak areas in the course. In the master course, reflection was only performed in a written workbook at the end of the course, and we see that the ongoing discussion throughout the course used in the bachelor course was a better approach. For the following semester, we will use the experiences to improve both courses.

\section{CONCLUSION}

The background to this paper was that students feel that they were rarely allowed to work with the personal development of both personal and interpersonal skills. The paper describes how we have developed a structure to explicitly work with the students' individual development areas for personal and interpersonal skills. Using this approach for three years and analysing the implementation, we can conclude that it has improved students' personal and interpersonal skills.

The results also highlight that students like to be challenged to change their professional conduct. They get support from both teachers and other students and have to force themselves to work with something that negatively impacts their usual way.

We have identified that this approach can be difficult to implement for larger groups of students because it is important to be able to follow each student's individual development, so one solution is to divide the class into smaller cohorts each coached by a teacher. We will continue to use this approach and compare it with the result from another course using the Habits of Mind framework.

\section{REFERENCES}

[1] Wikberg Nilsson Å., Normark J., Törlind, P. and Öhrling T. (2017). Experiences of educational reform: Implementation of CDIO at Industrial design engineering. Proceedings of the 13th International CDIO Conference.

[2] Crawley E. F., Malmqvist J., Östlund S. and Brodeur D. R. (2007). Rethinking Engineering Education: The CDIO Approach.

[3] Wikberg-Nilsson Å. and Törlind P. (2016). Student Competence Profiles: a complementary or competitive approach to CDIO. Proceedings of the 12th International CDIO Conference.

[4] Wikberg Nilsson $\AA$. And Törlind P. (2020). Implementation of workbooks as an active learning tool for Industrial Design Engineering. $7^{\text {th }}$ Development conference for Swedish Engineering Education, 161-163.

[5] Studentspegeln (2007) Högskoleverkets rapportserie 2007:20R Högskoleverket.

[6] CDIO Syllabus 2.0, Worldwide CDIO Initiative. http://www.cdio.org/benefits-cdio/cdiosyllabus/cdio-syllabus-topical-form

[7] Costa A. L. and Kallick B. (Eds.). (2008). Learning and leading with habits of mind: 16 essential characteristics for success. ASCD. 